\title{
Moving targets in 4D-CTs versus MIP and AIP: comparison of patients data to phantom data
}

\author{
Kai Joachim Borm¹, Markus Oechsner ${ }^{1}$, Moritz Wiegandt ${ }^{1,2}$, Andreas Hofmeister ${ }^{1,2}$, Stephanie E. Combs ${ }^{1,3}$ \\ and Marciana Nona Duma ${ }^{1,3^{*}}$ (D)
}

\begin{abstract}
Purpose: Maximum (MIP) and average intensity projection (AIP) CTs allow rapid definition of internal target volumes in a 4D-CT. The purpose of this study was to assess the accuracy of these techniques in a large patient cohort in combination with simulations on a lung phantom.

Methods: 4DCT data from a self-developed 3D lung phantom and from 50 patients with lung tumors were analyzed. ITVs were contoured in maximum (ITV MIP) and average intensity projection (ITV $\left.\mathrm{AIP}_{\mathrm{P}}\right)$ and subsequently compared to ITVs contoured in 10 phases of a $4 \mathrm{D}-\mathrm{CT}\left(\mathrm{ITV} \mathrm{V}_{10}\right)$. In the phantom study additionally a theoretical target volume was calculated for each motion and compared to the contoured volumes.

Results: ITV 10 overestimated the actual target volume by $9.5 \%$ whereas ITV $\mathrm{MIP}_{\mathrm{P}}$ and ITV AIP lead to an underestimation of $-1.8 \%$ and $-11.4 \%$ in the phantom study. The ITV MIP $\left(\right.$ ITV $\left._{\text {AIP }}\right)$ was in average $-10.0 \%(-18.7 \%)$ smaller compared to the ITV 10 . In the patient CTs deviations between ITV 10 and MIP/AIP were significantly larger (MIP: - 20.2\% AIP: -33.7\%) compared to this. Tumors adjacent to the chestwall, the mediastinum or the diaphragm showed lower conformity between ITV 10 and ITV MIP (ITV AIP) compared to tumors solely surrounded by lung tissue. Large tumor diameters $(>3.5 \mathrm{~cm})$ and large motion amplitudes $(>1 \mathrm{~cm})$ were associated with lower conformity between intensity projection $\mathrm{CTS}_{\mathrm{s}}$ and ITV $\mathrm{T}_{10-}$.

Conclusion: The application of MIP and AIP in the clinical practice should not be a standard procedure for every patient, since relevant underestimation of tumor volumes may occur. This is especially true if the tumor borders the mediastinum, the chest wall or the diaphragm and if tumors show a large motion amplitude.
\end{abstract}

Keywords: 4D-CT, MIP, AIP, Moving targets, SBRT

\section{Background}

Radiotherapy is an indispensible part of lung cancer treatment. It is estimated to be necessary in $50 \%$ of patients with small cell lung cancer (SCLC) and in over $60 \%$ of patients with non-small-cell lung cancer (NSCLC) in the course of the disease [1]. According to several studies, local control rates of over $95 \%$ can be achieved using stereotactic body radiotherapy (SBRT) [2, 3]. However, the treatment success hinges on an

\footnotetext{
*Correspondence: Marciana.Duma@mri.tum.de

'Department of Radiation Oncology, Klinikum rechts der Isar, TU München, Ismaninger Str. 22, 81675 Munich, Germany

${ }^{3}$ Institute of Innovative Radiotherapy (iRT), Helmholtz Zentrum München, Ingolstädter Landstraße 1, 85764, Oberschleißheim, Germany

Full list of author information is available at the end of the article
}

accurate target volume definition [4]. Target delineation in the lung is especially challenging due to tumor motion caused by respiration. The extent of motion depends on tumor localization and the patient's breathing pattern. For tumors located close to the diaphragm, amplitudes of over $2.5 \mathrm{~cm}$ have been measured [5, 6]. To detect tumor motion accurately, the use of four-dimensional computed tomography (4DCT) is a reliable tool. The 4D-CT generates multiple CT-images, each representing the tumor localization and extent at a certain breathing phase. Contouring of the tumor is usually performed in every single breathing phase with subsequent definition of an internal target volume (ITV) that takes the complete cycle of movement into account.

(c) The Author(s). 2018 Open Access This article is distributed under the terms of the Creative Commons Attribution 4.0 International License (http://creativecommons.org/licenses/by/4.0/), which permits unrestricted use, distribution, and reproduction in any medium, provided you give appropriate credit to the original author(s) and the source, provide a link to the Creative Commons license, and indicate if changes were made. The Creative Commons Public Domain Dedication waiver (http://creativecommons.org/publicdomain/zero/1.0/) applies to the data made available in this article, unless otherwise stated. 
There is good evidence that the use of a 4D-CT reduces motion artifacts and makes target localization more reliable compared to the 3D-CT [7, 8]. This results in better tumor coverage and a decrease of normal tissue irradiation during the treatment [9]. The ITV concept is commonly used for motion management. It ensures excellent tumor coverage but exposes a larger part of healthy lung tissue to radiation. Active motions management such as breathing coordination (gating) and tracking allow smaller treatment volumes and reduction of the dose in the organs at risk (OAR) [10, 11]. However these techniques require information on the tumor position in real time and therefore more complex technical equipment. Thus, the ITV concept remains the preferred motion management technique for many clinics. A major disadvantage of the 4D-CT is the fact that outlining gross tumor volumes (GTVs) in multiple CTs can be time-consuming, especially if a large tumor volume is contoured. Thus, since the introduction of the 4D-CT, alternative contouring methods have been discussed. On the one hand the ITV could be contoured on fewer breathing phases (usually the extreme ones) [9]. On the other hand the ITV might be contoured in average (AIP) or maximum intensity projection (MIP) [12, 13]. Several phantom studies concluded that MIP and AIP are reliable tools for target definition [14, 15]. However there is a lack of clinical studies confirming these findings. A few studies based on small patient collectives $(<$ 20 patients) showed that contouring in MIP might be an adequate option for smaller lung cancers (UICC Stage I) $[12,13,16]$. However a study by Cai et al. [17] using dynamic magnetic resonance imaging as reference concluded that 4D-CT MIP image might cause underdosing due to inaccurate target delineation. Thus the present literature is inconclusive and does not allow any clear conclusions. This study was performed to assess the error of MIP and AIP with special emphasis on tumor localization analyzing a large patient collective in combination with simulations of patient movements on a self-developed lung phantom $[18,19]$.

\section{Methods \\ Phantom}

A programmable phantom (Fig. 1) was developed based on a xy-table device by SunNuclear (Sun Nuclear Corporation, Melbourne, FL, USA) that enabled $\mathrm{x}$ and $\mathrm{y}$ movement. The device was combined with a self-developed equipment that allowed additional movement along the $\mathrm{z}$-axis to simulate 3 dimensional movement. Two spherical structures $(\varnothing 1 \mathrm{~cm}$ and $\varnothing 2 \mathrm{~cm})$ composed by water equivalent synthetic substance (RW3) were embedded in corkboards to resemble lung tissue. Tumor movement of 10 patients with large tumor motions (amplitudes $>0.5 \mathrm{~cm}$ ) out of the patient population described below were reconstructed by using the center of mass motion of the gross tumor volumes delineated in each of the 10 phases of 4D-CT scans. The movement pattern was then simulated with the phantom during CT imaging.

\section{Patient population}

Fifty patients with lung tumors treated with SBRT in our institution were chosen for this study. The diameter of the tumors ranged between $1.1 \mathrm{~cm}$ and $7.0 \mathrm{~cm}$; the median value was $3.1 \mathrm{~cm}$. The tumors were distributed in the upper $(n=23)$, middle $(n=12)$ and lower lobe $(n=$ $15)$ of the left $(n=22)$ and right lung $(n=28)$. In 10 cases the tumor was entirely surrounded by lung tissue. The remaining 40 tumors were adjacent to the mediastinum, the chest wall or the diaphragm (Fig. 2). The ethics
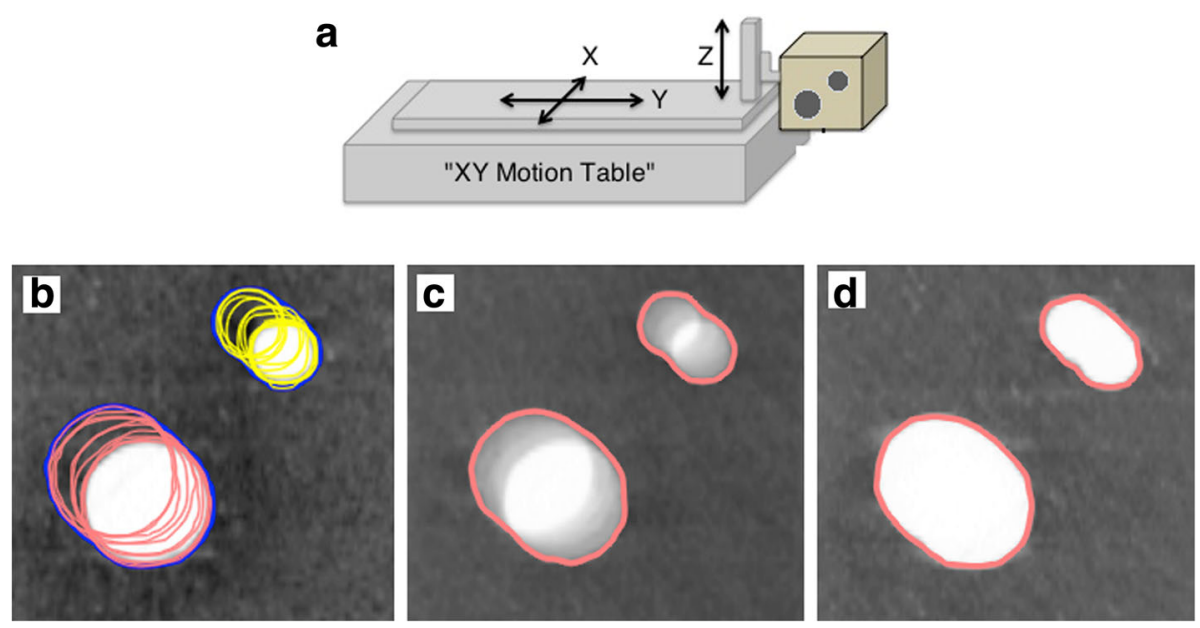

Fig. 1 Illustration of the lung phantom (a) and delineation examples of the two targets $(\varnothing 1 \mathrm{~cm}$ and $\varnothing 2 \mathrm{~cm}$ ) in one out of 10 phases of the 4DCT (b), in average intensity projection (c), in maximum intensity projection (d) 

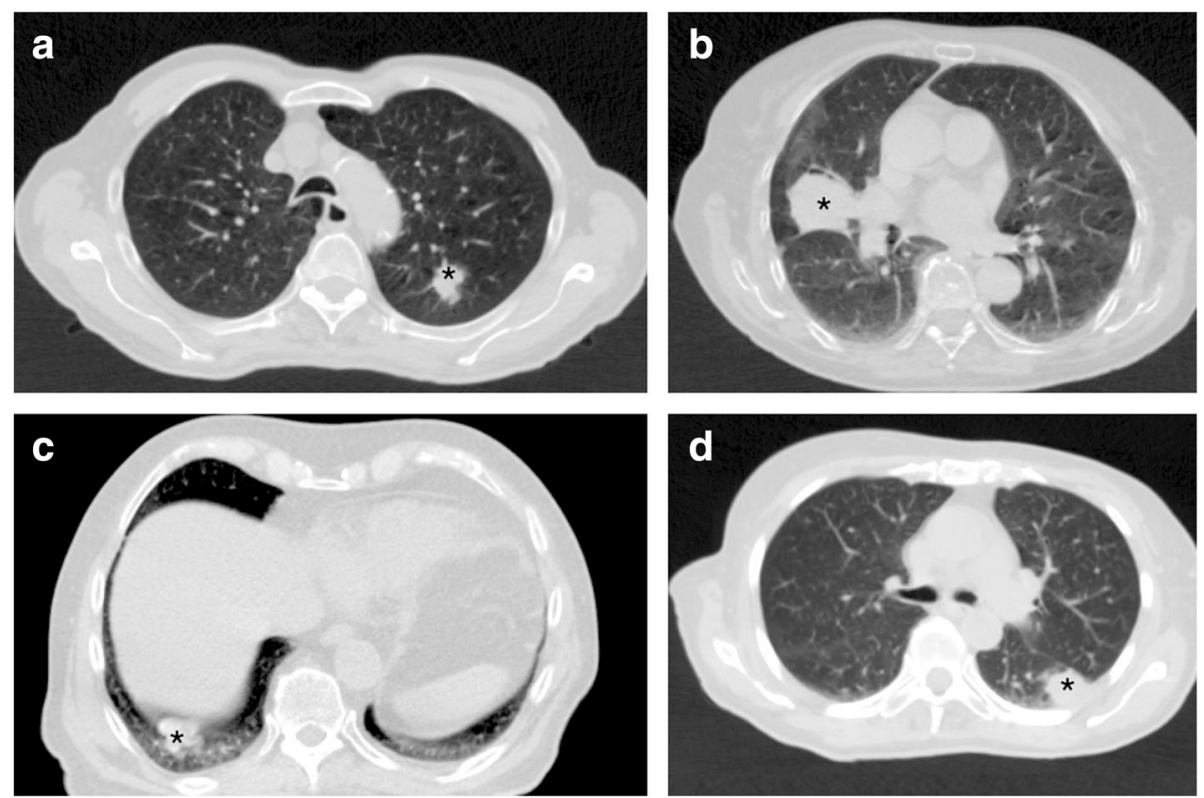

Fig. 2 Lung tumors $\left({ }^{*}\right)$ adjoining different structures in the thorax: A) only lung tissue; B) the mediastinum; C) the diaphragm; D) the chest wall

committee of Klinikum rechts der Isar/Technical University Munich approved this retrospective study. All patients gave their informed consent both informed and written before starting the radiotherapy that they will undergo $\mathrm{CT}$ radiotherapy treatment planning. Data from the CT radiotherapy treatment planning were retrospectively analyzed. Immobilization was achieved with a vacuum couch and low pressure foil (Medical Intelligence $\mathrm{GmbH}$, Schwabmünchen, Germany). During irradiation the patients received oxygen supply to further reduce respiratory movement. All plans were calculated for treatment on a Clinac Trilogy linear accelerator equipped with a 120 HD MLC (Varian Medical Systems, Palo Alto, CA, USA).

\section{D-CT data acquisition and contouring}

All CT data were acquired using a Somatom Emotion computer tomography (Siemens Medical Solutions, Erlangen, Germany). The breathing curve was detected by the Real-time Position Management system (RPM, Varian Medical Systems, Palo Alto, CA, USA). The spatial and temporal information was used to generate 4D-CTs containing 10 different breathing phases. The same technique was applied both for the lung cancer patients and the moving phantom. Contouring was performed using the Eclipse software Version 13.0 (Varian Medical Systems, Palo Alto, CA, USA). The visible volume of the tumor in the lung or in the phantom, respectively, was contoured slice by slice. [20]

The CT images were viewed and contoured in standard mediastinal and lung window settings $(-125 \mathrm{HU}$ to $225 \mathrm{HU}$ and $-1000 \mathrm{HU}$ and $200 \mathrm{HU}$ ). The contouring of the ITVs was performed manually following a visual approach. The same person performed all contouring to avoid interobserver variability $[18,19]$. For every structure a gross target volume (GTV) was defined in each of the 10 phases of the $4 \mathrm{D}-\mathrm{CT}$. Subsequently an $\mathrm{ITV}_{10}$ was generated by merging the $10 \mathrm{GTVs}$.

Additionally maximum (MIP) and average (AIP) intensity projection CTs were generated based on all phases of the $4 \mathrm{D}-\mathrm{CT}$, followed by contouring of an ITV $_{\text {MIP }}$ and ITV $_{\mathrm{AIB}}$, respectively.

\section{Analysis of target volumes}

For every patient the tumor size and diameter was measured in the treatment planning software. The size of the $\mathrm{ITV}_{10}, \mathrm{ITV}_{\mathrm{MIP}}$ and ITV $\mathrm{VAIP}_{\mathrm{P}}$ was derived from the treatment planning software after contouring. The average values of ITV pared to the average $\mathrm{ITV}_{10}$. Furthermore, to examine the conformity of the generated structures, we measured the overlap $\left(\mathrm{V}_{\mathrm{OL}}\right)$ of $\mathrm{ITV}_{10}$ and ITV $\mathrm{ITIP}_{\mathrm{M}}$ or ITV $\mathrm{ITIP}_{\mathrm{AI}}$ Subsequently, conformation numbers $(\mathrm{CN})$ were calculated according to van't Riet et al. [21] as follows: .

$$
C N=\frac{V_{O L}}{I T V_{I P}} \times \frac{V_{O L}}{I T V_{10}}
$$

$\mathrm{CN}$ : conformation number; $\mathbf{V}_{\mathrm{OL}}$ : overlapping volume between ITV 10 and ITV MIP $_{\text {or ITV }}$ AIP $_{\text {ITV }}$ IP: volume of intensity projection (IP) CTs MIP and AIP. ITV $\mathbf{1 0}_{\mathbf{1 0}}$ : volume of the target volume based on 10 phases of a 4D-CT. 
ITVs measured in the lung phantom (ITV $\mathrm{IO}_{10}, \mathrm{ITV}_{\mathrm{MIB}}$ ITV $_{\text {AIP }}$ ) were additionally compared to mathematically calculated volumes for each motion pattern and tumor diameter. Statistical analysis was performed using SPSS version 24.0 (IBM, Armonk, NY, USA). For all measurements mean values and standard deviation were calculated. The differences between the ITVs (e.g. ITV and $\left.\mathrm{ITV}_{10}\right)$ were tested for statistical significance using a two-sided paired T-test. The threshold for statistical significance was set to $p<0.05$.

\section{Results}

\section{Lung phantom}

For each motion a theoretical ITV was calculated taking the movement pattern and size of the target into account ("theoretical ITV"). This theoretical ITV ranged between $6.7 \mathrm{~cm}^{3}$ and $57.5 \mathrm{~cm}^{3}$, depending on target motion and size. The average ITV $\mathrm{Ialc}_{\text {cal }}$ for the small target (diameter $1 \mathrm{~cm}$ ) was $8.6 \pm 1.3 \mathrm{~cm}^{3}$ and for the large target (diameter $2 \mathrm{~cm}$ ) $50.3 \pm 4.8 \mathrm{~cm}^{3}$. The $\mathrm{ITV}_{10}$ were significantly larger compared to the calculated values, both for the small $\left(9.3 \pm 1.4 \mathrm{~cm}^{3}\right)$ as well as for the large target $\left(54.8 \pm 4.3 \mathrm{~cm}^{3}\right)$. Only in 1 out of 20 cases the ITV $_{10}$ was smaller $(-5,7 \%)$ than the calculated values. Contouring in MIP and AIP lead to underestimation of the target volume as compared to the ITV $\mathrm{Ialc}_{\text {c }} 98.1 \pm 5.3 \%$ and $88.6 \pm 5.1 \%$ of the calculated values were depicted by MIP and AIP. The ITV $V_{\text {AIP }}$ showed larger deviations from the calculated values $(-11.4 \%)$ than $\mathrm{ITV}_{\text {MIP }}$ and ITV $\mathrm{IT}_{10}$

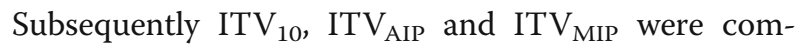
pared to each other. Even though ITV $\mathrm{IIIP}_{\text {and }} \mathrm{ITV}_{\mathrm{AIP}}$ were also significantly smaller compared to the $\mathrm{ITV}_{10}$ (ITV $\mathrm{IIP}_{\mathrm{M}}:-10.0 \%$; ITV $_{\mathrm{AIP}}$ : $-18.7 \%$ ) in the lung phantom, the differences between the different techniques were significantly smaller compared to the clinical study (Fig. 3). Correspondingly, the phantom conformation numbers between ITV 10 and ITV higher compared to the clinical data (Fig. 3). The mean value for the conformation numbers calculated for the ITV $_{\text {MIP }}$ and ITV AIP $_{\text {were }} 0.83$ and 0.79 . The ITVs of the
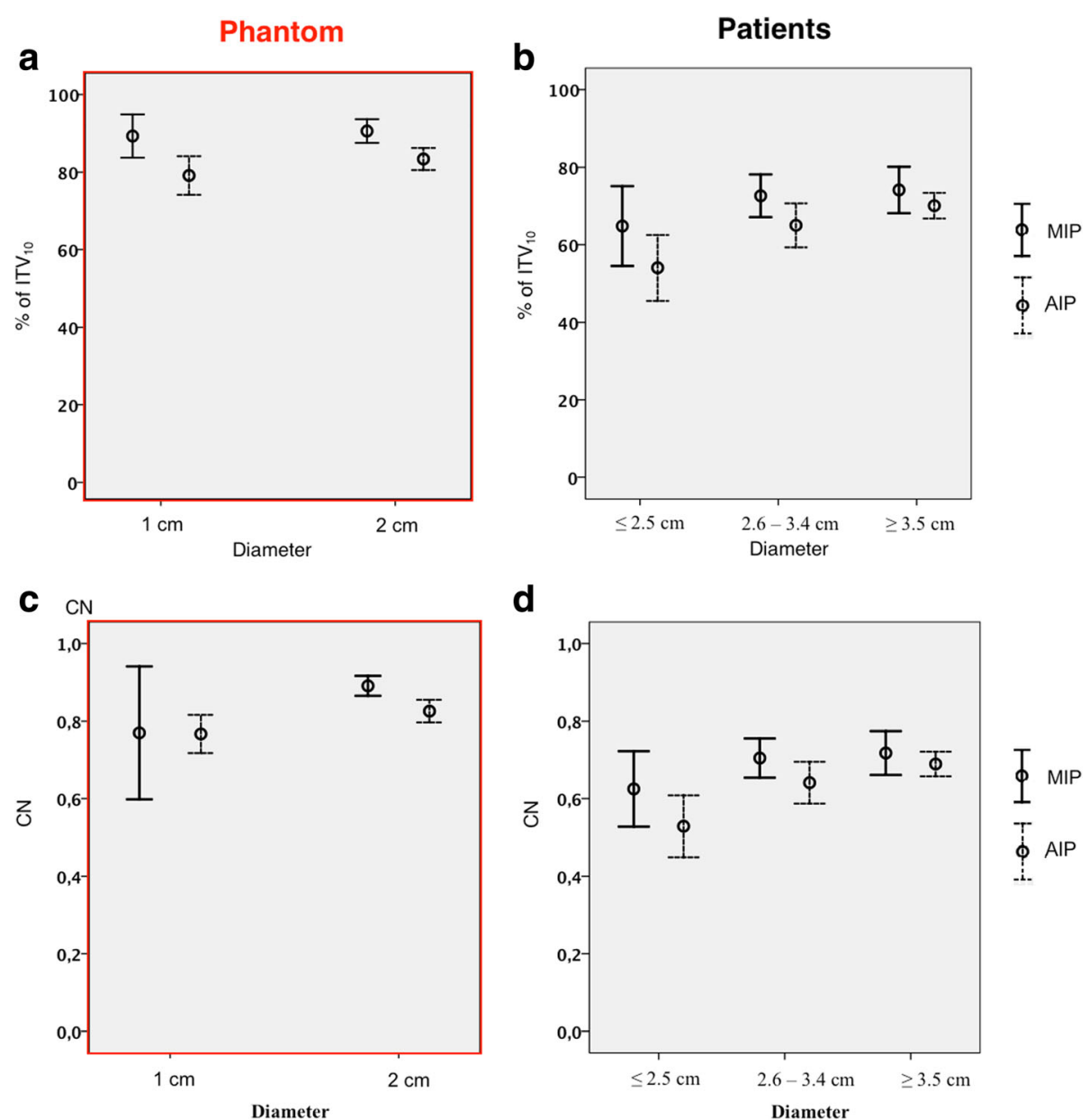

d

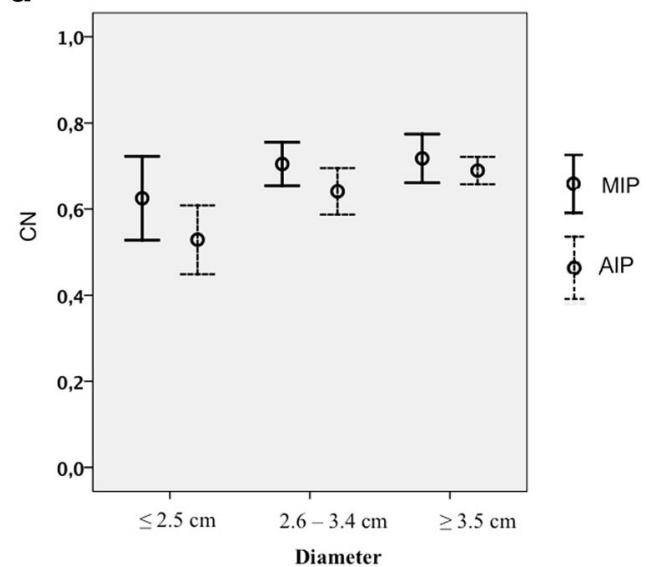

Fig. 3 Comparison of values measured in the phantom study $(\mathbf{a}, \mathbf{c})$ and in the clinical study $(\mathbf{b}, \mathbf{d})$. Relative size $(\mathbf{c}, \mathbf{d})$ and conformation numbers $(\mathrm{a}, \mathrm{b})$ of ITVs contoured in MIP and AIP in relation to the ITV 10 
$\varnothing 1 \mathrm{~cm}$ target showed a larger variability as well as slightly lower conformation numbers compared to the $\varnothing$ $2 \mathrm{~cm}$ target (Table 1$)$.

\section{Patients}

The average amplitude of tumor movement was $0.58 \pm$ $0.35 \mathrm{~cm}$. The mean $\mathrm{ITV}_{10}$ of all 50 patients was $27.6 \pm$ $36.3 \mathrm{~cm}^{3}$. ITVs based on the MIP or AIP were significantly $(p<0.001)$ smaller compared to the $\mathrm{ITV}_{10}$. The ITV $V_{\text {MIP }}$ had an average value of $21.0 \pm 29,7 \mathrm{~cm}^{3}$, which corresponded to $73.4 \pm 15.6 \%$ of the ITV $_{10}$. The ITVs contoured in the AIP CTs were even smaller with an avarage value of $19.2 \pm 27.7 \mathrm{~cm}^{3}(64.8 \pm 13.4 \%$ of the ITV 10 ). The mean overlapping volume of $\mathrm{ITV}_{10}$ and ITV $_{\text {MIP }}$ was $20.6 \pm 29.6 \mathrm{~cm}^{3} .71 .0 \pm 13.9 \%$ of ITV $_{10}$ were covered in average by the ITV $\mathrm{TIP}_{\text {. The ITV }}$ AIP covered $63.7 \pm 12.8 \%$ of the $\operatorname{ITV}_{10}\left(19.0 \pm 27.4 \mathrm{~cm}^{3}\right)$. The mean value for the calculated conformity index was $0.69 \pm 0.13$ in the MIP and $0.63 \pm 0.12$ in the AIP.

Figure 4 depicts the measured target volumes in MIP and AIP considering the surrounding tissue and the tumor movements. MIP and AIP showed the best concordance with the ITV 10 if the tumor was solely surrounded by lung tissue. For tumors bordering other structures, such as the chest wall or the mediastinum the difference between ITV $_{10}$ and both intensity projection CTs were significantly $(<0.05)$ larger. The largest deviations between the different contouring techniques $\left(\operatorname{ITV}_{10}, \mathrm{ITV}_{\mathrm{MIB}} \mathrm{ITV}_{\mathrm{AIP}}\right)$ were found for tumors merging the diaphragm and abdominal organs (> 50\% volume difference). MIP showed better conformity with the ITV $\mathrm{I}_{10}$ than AIP in all measurements, except for tumors merging to the diaphragm. All values are summarized in Table 2.

Also, the tumor size (Fig. 3) and the motion amplitude (Fig. 4) had an influence on the relative differences between ITV 10 and ITV MIP $_{10}$ or ITV diameter of $<2.5 \mathrm{~cm}$ only $64.8 \pm 17.9 \%$ (or $54.0 \pm 14.7 \%$ ) of the ITV 10 were covered in maximum (or average) intensity projection CTs. Tumors with a diameter that ranged between $2.5 \mathrm{~cm}$ and $3.5 \mathrm{~cm}$ covered $72.6 \pm 11.5 \%$ in MIP and $65.0 \pm 11.8 \%$ in AIP of the ITV 10 . Large tumors (diameter $>3.5 \mathrm{~cm}$ ) contoured in MIP or AIP $(74.1 \pm 11.7 \%$; $63.7 \pm 12.8 \%)$ showed the best conformity to the ITV 10 . Larger tumor amplitudes were associated with poorer conformity between intensity projection CTs and the ITV 10 . The differences between ITV ITV $\mathrm{V}_{\text {AIP }}$ were $11.6 \%$ larger in patients with amplitudes of $>1 \mathrm{~cm}$ compared the group with tumor motions of < $0.5 \mathrm{~cm}$ (Table 2).

\section{Discussion}

Our results show that ITVs contoured in MIP and AIP differ significantly from ITVs contoured in 10 phases of a 4D-CT. In the clinical study, average deviations of approximately $-25 \%$ were observed with even larger differences for tumors that border the mediastinum, the chest wall or the diaphragm. The data acquired with the lung phantom shows that ITV 10 overestimates the target volume to a certain degree. ITV $\mathrm{IIP}_{\mathrm{MI}}$ and ITV $\mathrm{IIP}_{\mathrm{AI}}$ on the other hand underestimate the target volume und therefore do not reliably encompass the tumor tissue in all cases. Differences between ITV 10 and ITV $\mathrm{IIP}_{\text {MIP }}$ were substantially larger in the clinical study compared to the phantom study.

A study of Park et al. [14] analyzed the accuracy of MIPs for various target motions using a programmable lung phantom. Two targets inserted in a cork block were moved with irregular target motions along the superior-inferior direction and the two-dimensional target span in moving direction was measured and compared to the theoretical values. They concluded that the MIP accurately reflects the range of motions for regular target motions. However the validity of the results for the clinical practice is limited, since target motion was simulated in only one direction, no volume assessment was performed and tumors in patients seldom undergo a regular movement pattern. Simon et al. [15] used a lung tumor phantom to simulate anterior-posterior movements to compare AIP and MIP ITVs to calculated theoretical values. The error on volume assessment ranged from.

$-40 \%$ to $-9 \%$ for the AIP and from -3 to $12 \%$ for the MIP. The average deviations from the calculated values measured in our study in the lung phantom were also within this range (Table 1). The authors concluded that MIPs could be used for target definition of moving targets in a $4 \mathrm{D}-\mathrm{CT}$, as it seems to encompass the tumor movement. However, before this conclusion is drawn,

Table 1 Measured values in the lung phantom. Average absolute volumes $\pm S D$ of the $\operatorname{ITV}_{10}, \operatorname{ITV}_{\mathrm{MIP}}, \mathrm{TV}$ AIP in $\mathrm{cm}^{3}$, (relative volumes $\pm S D$ as percentage of the calculated values $-\operatorname{ITV}_{\text {calc }}$ in \%), conformation numbers (CN) of ITV $\mathrm{MIP}_{\text {and }} \operatorname{ITV}_{\text {AIP }}$ with the ITV $10 . \mathrm{n}=$ number of movement patterns

\begin{tabular}{|c|c|c|c|c|c|c|c|}
\hline$\varnothing$ & $\mathrm{n}=$ & ITV calc & $\mathrm{ITV}_{10}$ & ITV & $\mathrm{ITV}_{\mathrm{AIP}}$ & $\mathrm{CN}_{\mathrm{MIP}}$ & $\mathrm{CN}_{\mathrm{AIP}}$ \\
\hline $1.0 \mathrm{~cm}$ & 10 & $8.6 \pm 1.3 \mathrm{~cm}^{3}$ & $\begin{array}{l}9.3 \pm 1.5 \mathrm{~cm}^{3} \\
(109.9 \pm 13.8 \%)\end{array}$ & $\begin{array}{l}8.3 \pm 10.9 \mathrm{~cm}^{3} \\
(97.4 \pm 7.1 \%)\end{array}$ & $\begin{array}{l}7.3 \pm 0.9 \mathrm{~cm}^{3} \\
(86.2 \pm 5.4 \%)\end{array}$ & $0.77 \pm 0.2$ & $\overline{0.77 \pm 0.1}$ \\
\hline $2.0 \mathrm{~cm}$ & 10 & $50.3 \pm 4.8 \mathrm{~cm}^{3}$ & $\begin{array}{l}54.8 \pm 4.2 \mathrm{~cm}^{3} \\
(109.2 \pm 5.8 \%)\end{array}$ & $\begin{array}{l}49.6 \pm 3.8 \mathrm{~cm}^{3} \\
(98.8 \pm 3.0 \%)\end{array}$ & $\begin{array}{l}45.7 \pm 4.1 \mathrm{~cm}^{3} \\
(90.9 \pm 3.6 \%)\end{array}$ & $0.89 \pm 0.0$ & $0.89 \pm 0.0$ \\
\hline Total & 20 & $29.4 \pm 21.7 \mathrm{~cm}^{3}$ & $\begin{array}{l}32.1 \pm 23.5 \mathrm{~cm}^{3} \\
(109.5 \pm 10.3 \%)\end{array}$ & $\begin{array}{l}28.9 \pm 21.4 \mathrm{~cm}^{3} \\
(98.1 \pm 5.3 \%)\end{array}$ & $\begin{array}{l}26.5 \pm 19.9 \mathrm{~cm}^{3} \\
(88.6 \pm 5.1 \%)\end{array}$ & $0.79 \pm 0.2$ & $0.83 \pm 0.1$ \\
\hline
\end{tabular}



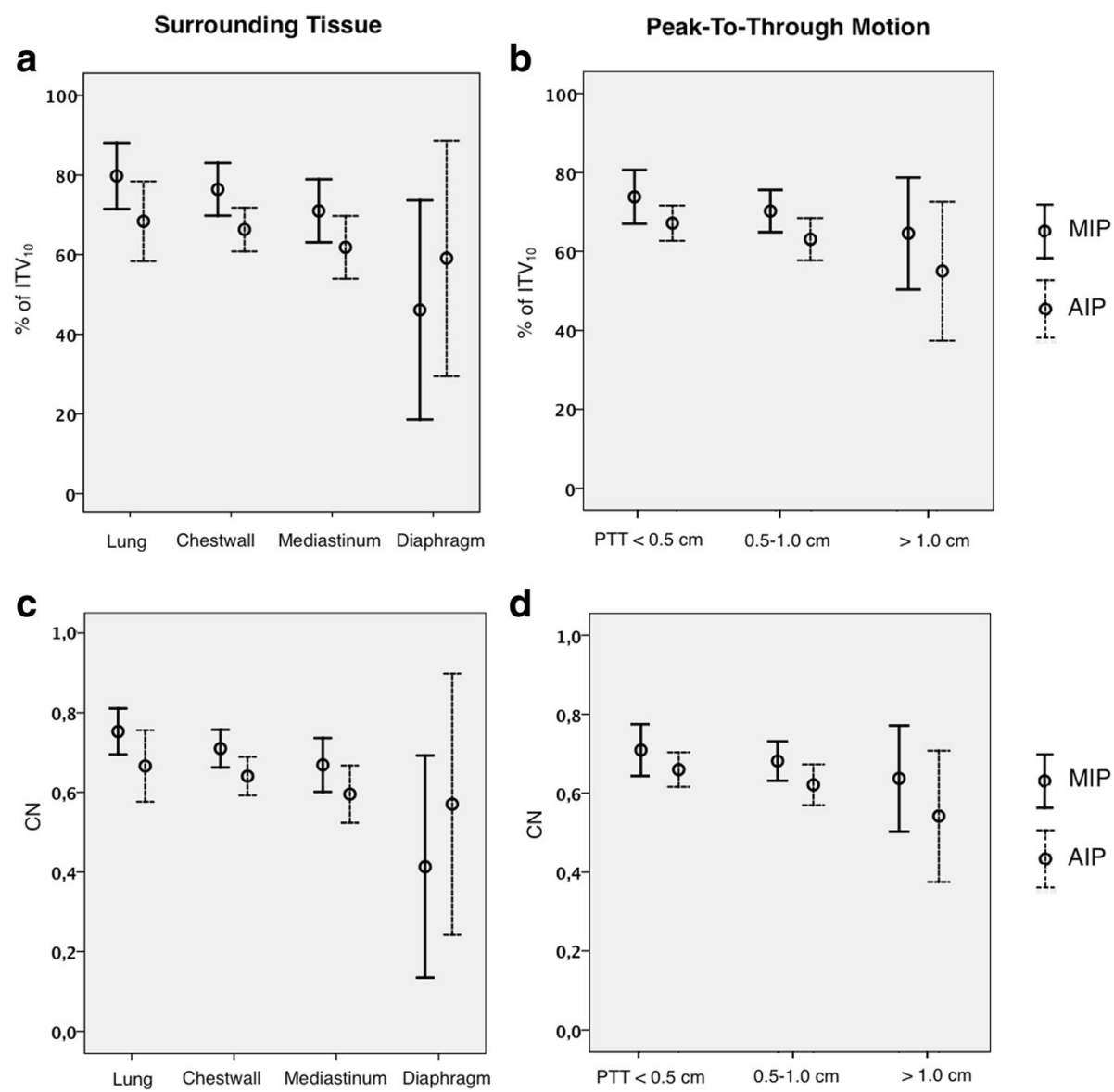

Fig. 4 Impact of the surrounding tissue $(a, c)$ and motion amplitude $(b, d)$ on the contoured target volumes in MIP and AIP. Relative size (a,b) in \% and conformation numbers ( $c, d)$ of ITVs contoured in MIP and AIP in regard to the ITV ${ }_{10}$ CN: conformation number, PTT: peak-to-through motion

Table 2 Measured values for ITV MIP and ITV AIP in dependence on the surrounding tissue and the tumor size in a 4D-CT. Relative size in \% in regard to the ITV 10 and overlapping volume $\left(V_{O L}\right)$ in $\mathrm{cm}^{3}$ as well as conformation numbers $(C N)$ of IT $V_{\text {MIP }}$ and ITV $\operatorname{ITV} 10$

\begin{tabular}{|c|c|c|c|c|c|c|c|c|}
\hline & & \multirow[t]{2}{*}{$\mathrm{n}=$} & \multicolumn{3}{|l|}{ MIP } & \multicolumn{3}{|l|}{ AIP } \\
\hline & & & $\%$ & $V_{\mathrm{OL}}$ & $\mathrm{CN}$ & $\%$ & $V_{O L}$ & $\mathrm{CN}$ \\
\hline \multirow[t]{4}{*}{ Tumor surrouding } & only lung tissue & 10 & $79.8 \pm 11.6$ & $77.5 \pm 9.6$ & $0.75 \pm 0.1$ & $68.4 \pm 14.1$ & $67.5 \pm 13.3$ & $0.67 \pm 0.1$ \\
\hline & chestwall & 20 & $76.4 \pm 14.1$ & $73.6 \pm 11.3$ & $0.71 \pm 0.1$ & $66.3 \pm 11.8$ & $65.2 \pm 11.0$ & $0.64 \pm 0.1$ \\
\hline & mediastinum & 16 & $71.0 \pm 15.4$ & $68.9 \pm 13.9$ & $0.67 \pm 0.1$ & $61.8 \pm 15.3$ & $60.7 \pm 14.5$ & $0.59 \pm 0.1$ \\
\hline & diaphragm & 4 & $46.1 \pm 11.1$ & $43.7 \pm 11.1$ & $0.41 \pm 0.1$ & $59.1 \pm 11.9$ & $58.0 \pm 12.4$ & $0.57 \pm 0.1$ \\
\hline \multirow[t]{3}{*}{ Tumor size (Diameter) } & $\leq 2.5 \mathrm{~cm}$ & 14 & $67.2 \pm 19.4$ & $64.8 \pm 17.9$ & $0.63 \pm 0.2$ & $55.2 \pm 16.0$ & $54.0 \pm 14.7$ & $0.53 \pm 0.1$ \\
\hline & $2.6-3.4 \mathrm{~cm}$ & 19 & $75.1 \pm 13.9$ & $72.6 \pm 11.5$ & $0.72 \pm 0.1$ & $66.0 \pm 12.5$ & $65.0 \pm 11.8$ & $0.64 \pm 0.1$ \\
\hline & $\geq 3.5 \mathrm{~cm}$ & 17 & $76.7 \pm 13.3$ & $74.1 \pm 11.7$ & $0.71 \pm 0.1$ & $71.3 \pm 6.9$ & $70.1 \pm 6.4$ & $0.69 \pm 0.1$ \\
\hline \multirow[t]{3}{*}{ PTT } & $<0.5 \mathrm{~cm}$ & 21 & $77.1 \pm 16.8$ & $73.8 \pm 15.0$ & $0.71 \pm 0.1$ & $68.4 \pm 10.4$ & $67.2 \pm 9.9$ & $0.65 \pm 0.1$ \\
\hline & $0.5-1 \mathrm{~cm}$ & 22 & $72.5 \pm 13.8$ & $70.2 \pm 12.1$ & $0.68 \pm 0.1$ & $64.1 \pm 12.8$ & $63.1 \pm 12.1$ & $0.62 \pm 0.1$ \\
\hline & $>1 \mathrm{~cm}$ & 7 & $65.5 \pm 16.3$ & $64.6 \pm 15.3$ & $0.63 \pm 0.1$ & $55.9 \pm 20.2$ & $55.0 \pm 19.0$ & $0.54 \pm 0.1$ \\
\hline Total & & 50 & $73.4 \pm 15.6$ & $71.0 \pm 13.9$ & $0.69 \pm 0.1$ & $64.7 \pm 13.5$ & $63.7 \pm 12.8$ & $0.63 \pm 0.1$ \\
\hline
\end{tabular}


the question must be raised whether these results from idealized phantom conditions can be transferred to the clinical situation where serrated tumor shapes, complex tumor movements and irregular density distributions occur.

The available clinical date is inconclusive and based on small groups of patients only. Bradley et al. [12] compared MIP, AIP and helical 4D-CT images of 20 inoperable peripheral stage I lung tumors to determine the best definition method for stereotactic body radiation therapy. MIP-defined ITVs were significantly larger than helical and AIP defined ITVs. They concluded MIP is superior to AIP in order to depict tumor motion. However, since no comparison to the $\mathrm{ITV}_{10}$ was done, the question whether the actual tumor is represented accurately by the ITV $\mathrm{IIP}_{\text {MI }}$ remains unclear in this study. A study by Murihead et al. [13] collected 4D-CT data from 14 patients with NSCLC. ITVs were contoured in 10 phases of a $4 \mathrm{D}-\mathrm{CT}$ and in MIP. The $\mathrm{ITV}_{10}$ served as a reference volume to evaluate the precision of the MIP. In average $19 \%$ of the $\mathrm{ITV}_{10}$ were not enclosed by the $\mathrm{ITV}_{\mathrm{MIP}}$. This is in accordance with our findings showing an insufficient coverage of the ITV $\mathrm{IO}_{10}$ in MIP and AIP. The authors proposed the use of the MIP image target delineation for patients with stage I disease, since only minor deviations (6.1\%) occurred in this subgroup, which consisted of 2 patients in the study. Contrary to this, in our study small targets $(\varnothing<2.5 \mathrm{~cm}$ in the clinical study, $\varnothing 1 \mathrm{~cm}$ in the phantom study) resulted in the poorest conformity between MIP and the $\mathrm{ITV}_{10}$ (Fig. 3). Underberg et al. [16] analyzed 4D-CT data from a phantom and from 11 patients with small Stage I lung cancer. ITVs generated in all 10 phases were compared with ITVs generated in MIP. The average ratio between $\mathrm{ITV}_{10}$ and ITV $\mathrm{IIP}_{\text {Mas }} 1.04$ for the phantom study and 1.07 in scans of the patients. The center of mass differed by only 0.4 or $0.5 \mathrm{~mm}$, respectively. The authors concluded that MIPs are a reliable clinical tool for generating ITVs from a 4DCT data set. Even though not explicitly mentioned by the authors it appears in the figures that narrow window settings (e.g. mediastinal window) have been used for contouring. As shown in current literature these windows do not accurately reflect moving targets and might have a major effect on the results [18] .

According to our results MIP does not accurately depict the target volume as contoured in each of the 10 phases of a $4 \mathrm{D}-\mathrm{CT}$. The deviations between $\mathrm{ITV}_{10}$ and ITV $_{\text {MIP/AIP }}$ in the clinical study (MIP: - 20.2\% AIP: $-33.7 \%$ ) were almost twice as large as in the phantom study (MIP -10.0\% AIP -18.7\%). Even though the MIP reflected the calculated values in the phantom study well, relevant underestimation of the target size needs to be expected in the clinical practice. This is especially true if the tumor borders the mediastinum, the chest wall or the diaphragm and if tumors show an extensive motion amplitude. For these tumors the deviations were particularly large. The reason for this is a loss of contrast between tumor and surrounding tissue by using maximum values for every voxel, leading to underestimation of the tumor in the overlapping areas. The large deviations using MIP for tumors bordering soft tissues could be also observer dependent, in particular as a visual approach was followed instead of automatic contouring. Since extreme movement of tumors bordering soft tissue impedes definition of an ITV, other treatment options like robotic radio surgery or breath hold techniques should be taken into consideration, in these situations [22, 23].

The 4D-CT has been adopted as a standard modality for target delineation in lung tumors because it represents moving targets significantly better than slow 3D-CTs. Nakamuru et al. [7] evaluated in 32 lung cancer patients the geometrical differences in target volumes between slow CT- and 4D CT- imaging for lung tumors. They observed that target volumes acquired in slow $3 \mathrm{D}-\mathrm{C}$ Ts are approximately $25 \%$ smaller compared to target volumes contoured in a $4 \mathrm{D}-\mathrm{CT}$. In our study MIP ITVs were on average $20.2 \%$ smaller than the $\mathrm{ITV}_{10}$, which, by extrapolation, can be compared to the previous reported difference between the slow 3D-CTs and ITV $_{10}$. Thus, the use of MIP comes with a risk of losing additional and relevant information obtained by analyzing all phases of the 4D-CT.

The current study focuses solely on the impact of MIP and AIP on definition of the ITV. However, it needs to be also taken into account that the data set used for treatment planning has an important effect on the dose distribution within the tumor and the OAR [20, 24]. Due to respiration-induced density variations within the ITV 3D, dose calculation based on free-breating-, MIP-, AIP- or mid-ventilation CT datasets only estimates the actual dose in the tumor [10]. The dosimetric characteristics of plans based on AIP and mid-ventilation CTs are reported to be similar to those of FB- CTs [25]. Treatment plans calculated on a MIP CT dataset on the other hand may not be not appropriate for OAR dose assessment [20]. A promising approach to cope with density variations is the use of 4D-CT treatment planning with respiration-correlated assignment of the treatment plan's monitor units to the different respiration phases of a 4D-CT and subsequent rigid and non-rigid registration [10].

A potential limitation of this study is the impact of interobserver variability on the contouring of lung tumors in a 4D-CT. Louie et al. [26] showed that the percentage shared internal target volume of 6 physicians contouring 10 different tumors ranged from 31.1 to $83.3 \%$. Therefore the observed effect might differ in some cases. Nevertheless we cannot recommend the MIP (and AIP) as a standard procedure in clinical practice, since relevant underestimation of target motion and tumor 
volumes may occur. Whenever MIP is used for contouring, we strongly recommend to double check that the ITV encompasses the delineated target in each of the 10 phase of the 4D-CT.

\section{Conclusion}

Contouring in maximum or average intensity projection CTs reduces the time that is required to define an internal target volume. Even though the MIP reflected the calculated values in the phantom study well, relevant underestimation of the target size can be expected in the clinical practice. This is especially true if the tumor borders the mediastinum, the chest wall or the diaphragm and if tumors show a large motion amplitude. Therefore neither AIP nor MIP can be unquestionably recommended for target delineation. Whenever MIP is used for contouring, it needs to ensure that ITV encompasses the delineated target in every phase of the 4D-CT.

\section{Abbreviations}

4DCT: Four-dimensional computed tomography; AIP: Average intensity projection; CN: Conformation numbers; GTVs: Gross tumor volumes; HU: Hounsfield units; ITV: Internal target volume; ITV 10 : ITV based on 10 4DCT phases; ITV AIP: ITV based on AIP; ITV calc: Theoretical calculated ITV ; ITV MIP: ITV based on MIP; MIP: Maximum intensity projection; NSCLC: Non-smallcell lung cancer; OAR: Organs at risk; SBRT: Stereotactic body radiotherapy; SCLC: Small cell lung cancer; $V_{O}$ : Overlapping volume

\section{Availability of data and material}

The datasets used and/or analysed during the current study are available from the corresponding author on reasonable request.

\section{Funding}

External funding: not available.

The authors are employed as care providers/researchers by Klinikum rechts der Isar, Technical University Munich, Germany.

\section{Authors' contributions}

MND and $M O$ initiated the project. $\mathrm{KJB}, \mathrm{MW}$ and $\mathrm{AH}$ generated and analyzed the data. MND, KJB, SEC performed patient care. KJB, MO and MND wrote the manuscript. KJB, MO, SEC and MND finalized the manuscript. All authors read and approved the final manuscript.

\section{Ethics approval and consent to participate}

The ethics committee of Klinikum rechts der Isar, TU München has approved this retrospective study (475/17S). All patients gave their informed consent to undergo $C T$ for radiotherapy treatment planning. The need for a second informed consent for this retrospective study on CT datasets was deemed unnecessary and has been waived by the IRB.

\section{Consent for publication}

Not applicable.

\section{Competing interests}

MND is an editor of BMC cancer. All other authors declare that they have no competing interests.

\section{Publisher's Note}

Springer Nature remains neutral with regard to jurisdictional claims in published maps and institutional affiliations.

\section{Author details}

'Department of Radiation Oncology, Klinikum rechts der Isar, TU München, Ismaninger Str. 22, 81675 Munich, Germany. ${ }^{2}$ Medical School Technische Universität München, Ismaninger Str. 22, 81675 Munich, Germany. ${ }^{3}$ Institute of Innovative Radiotherapy (iRT), Helmholtz Zentrum München, Ingolstädter Landstraße 1, 85764, Oberschleißheim, Germany.

Received: 6 March 2018 Accepted: 28 June 2018

Published online: 24 July 2018

\section{References}

1. Tyldesley $\mathrm{S}$, et al. Estimating the need for radiotherapy for lung cancer: an evidence-based, epidemiologic approach. Int J Radiat Oncol Biol Phys. 2001; 49(4):973-85.

2. Wulf J, et al. Stereotactic radiotherapy of targets in the lung and liver. Strahlenther Onkol. 2001;177(12):645-55.

3. Rusthoven $\mathrm{KE}$, et al. Multi-institutional phase $\mathrm{I} / \mathrm{II}$ trial of stereotactic body radiation therapy for lung metastases. J Clin Oncol. 2009;27(10):1579-84.

4. Ong CL, et al. Treatment of large stage I-II lung tumors using stereotactic body radiotherapy (SBRT): planning considerations and early toxicity. Radiother Oncol. 2010;97(3):431-6.

5. Shimizu S, et al. Detection of lung tumor movement in real-time tumortracking radiotherapy. Int J Radiat Oncol Biol Phys. 2001;51(2):304-10.

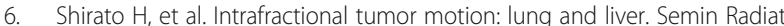
Oncol. 2004;14(1):10-8

7. Nakamura $\mathrm{M}$, et al. Geometrical differences in target volumes between slow $\mathrm{CT}$ and $4 \mathrm{D} C \mathrm{~T}$ imaging in stereotactic body radiotherapy for lung tumors in the upper and middle lobe. Med Phys. 2008;35(9):4142-8.

8. Vedam SS, et al. Acquiring a four-dimensional computed tomography dataset using an external respiratory signal. Phys Med Biol. 2003;48(1): 45-62.

9. Rietzel $\mathrm{E}$, et al. Design of 4D treatment planning target volumes. Int J Radiat Oncol Biol Phys. 2006;66(1):287-95

10. Guckenberger $M$, et al. Four-dimensional treatment planning for stereotactic body radiotherapy. Int J Radiat Oncol Biol Phys. 2007;69(1):276-85.

11. Keall P. 4-dimensional computed tomography imaging and treatment planning. Semin Radiat Oncol. 2004;14(1):81-90.

12. Bradley JD, et al. Comparison of helical, maximum intensity projection (MIP), and averaged intensity (AI) 4D CT imaging for stereotactic body radiation therapy (SBRT) planning in lung cancer. Radiother Oncol. 2006; 81(3):264-8

13. Muirhead R, et al. Use of maximum intensity projections (MIPs) for target outlining in 4DCT radiotherapy planning. J Thorac Oncol. 2008:3(12):1433-8.

14. Park K, et al. Do maximum intensity projection images truly capture tumor motion? Int J Radiat Oncol Biol Phys. 2009;73(2):618-25.

15. Simon $L$, et al. Initial evaluation of a four-dimensional computed tomography system, using a programmable motor. Radiat Oncol Phys. 2006;7(4):50-65.

16. Underberg RW, et al. Use of maximum intensity projections (MIP) for target volume generation in 4DCT scans for lung cancer. Int J Radiat Oncol Biol Phys. 2005;63(1):253-60.

17. Cai J, Read PW, Sheng K. The effect of respiratory motion variability and tumor size on the accuracy of average intensity projection from fourdimensional computed tomography: an investigation based on dynamic MRI. Med Phys. 2008;35(11):4974-81.

18. Borm KJ, et al. The importance of surrounding tissues and window settings for contouring of moving targets. Strahlenther Onkol. 2015; 191(9):750-6.

19. Borm KJ, et al. The impact of CT window settings on the contouring of a moving target: a phantom study. Clin Radiol. 2014;69(8):e331-6.

20. Oechsner $M$, et al. Interobserver variability of patient positioning using four different $C T$ datasets for image registration in lung stereotactic body radiotherapy. Strahlenther Onkol. 2017:193(10):831-9.

21. van't Riet $A$, et al. A conformation number to quantify the degree of conformality in brachytherapy and external beam irradiation: application to the prostate. Int J Radiat Oncol Biol Phys. 1997;37(3):731-6.

22. Katoh $\mathrm{N}$, et al. Clinical outcomes of stage I and IIA non-small cell lung cancer patients treated with stereotactic body radiotherapy using a realtime tumor-tracking radiotherapy system. Radiat Oncol. 2017;12(1):3.

23. Takao S, et al. Intrafractional baseline shift or drift of lung tumor motion during gated radiation therapy with a real-time tumor-tracking system. Int J Radiat Oncol Biol Phys. 2016:94(1):172-80.

24. Ehrbar S, et al. ITV, mid-ventilation, gating or couch tracking - a comparison of respiratory motion-management techniques based on 4D dose calculations. Radiother Oncol. 2017;124(1):80-8. 
25. Tian Y, et al. Dosimetric comparison of treatment plans based on free breathing, maximum, and average intensity projection CTs for lung cancer SBRT. Med Phys. 2012;39(5):2754-60

26. Louie AV, et al. Inter-observer and intra-observer reliability for lung cancer target volume delineation in the $4 \mathrm{D}-\mathrm{CT}$ era. Radiother Oncol. 2010;95(2):166-71.

Ready to submit your research? Choose BMC and benefit from:

- fast, convenient online submission

- thorough peer review by experienced researchers in your field

- rapid publication on acceptance

- support for research data, including large and complex data types

- gold Open Access which fosters wider collaboration and increased citations

- maximum visibility for your research: over $100 \mathrm{M}$ website views per year 